\title{
Scientometrical review of Dinoflagellate studies in Brazil
}

\author{
Pietro Martins Barbosa Noga ${ }^{1 *}\left(\odot\right.$ and Doriedson Ferreira Gomes ${ }^{1} \Subset$
}

Received: October 27, 2017

Accepted: March 21, 2018

\begin{abstract}
Scientific production in developing countries is currently increasing, but there is still an unbalanced distribution of scientific production between developed and developing countries. With the need to elucidate disparities in scientific production, this paper aims to review publications on dinoflagellates in Brazil by discussing spatial and temporal trends. A search for papers referring to dinoflagellates was performed in the Scopus database up to the year of 2016. A total of 125 papers were found, but only 106 were selected according to established criteria. A linear regression was used to evaluate the increasing temporal trend in production and non-parametric ANOVA for comparisons among study categories. Dinoflagellate and toxic taxa-based publications have increased from 1990 to 2016 for Brazil, yet a discrepancy in performance with other countries is evident. There is a constant increase in the number of functional ecology studies focusing on toxin-producing species related to blooms. The spatial distribution of production in Brazil revealed that the Southeast and South regions are the most productive, where there more graduate programs and advanced research centers. Investments in this ecological subject are fundamental to the management of biodiversity, and a call for more equal resource distribution in developing countries is imperative.
\end{abstract}

Keywords: Dinophyta, harmful algae blooms, phytoplankton, public investments, scientometry

\section{Introduction}

Reducing discrepancies in scientific production between developed and developing countries is recognized as a great challenge. The United Nations has called attention to these inequalities suggesting the necessity of bringing the scientific community closer to each other (Annan 2003). According to the United Nations Educational, Scientific and Cultural Organization (UNESCO 2001) developed countries were responsible for more than $80 \%$ of the global investment in scientific research and development
(R\&D) in 1997. North American and European countries dominate publication production, which is mainly due to these countries committing more robust resources to $R \& D$, resulting in the greater number of publications (Holmgren \& Schnitzer 2004). The origin of investments in $R \& D$ in developed countries is with industry, which is responsible for more than a half-percent of all investments. In the United States, $66 \%$ of R\&D investments are funded by the industrial sector. Other countries, such as Germany (66\%), China (75\%) and South Korea (73\%), are constantly increasing their investments in scientific production, while 1 Programa de Pós-Graduação em Ecologia e Biomonitoramento, Instituto de Biologia, Universidade Federal da Bahia, 40170-115,
Salvador, BA, Brazil

* Corresponding author: profpietrobarbosa@gmail.com 
Brazil receives only $47 \%$ of its investment from tradeindustry (UNESCO 2001).

Knowledge of gaps and voids in particular scientific areas is mandatory for discussing important questions that may contribute to the improvement of scientific development, especially in developing countries such as Brazil. Scientometry, thus, is a relevant tool for assessing the main trends and patterns in dinoflagellate-based studies. This technique has been used to understand the patterns of scientific production (publications) in areas such as limnology (Melo et al. 2006), macrophyte biology (Padial et al. 2008), water quality indexes (Alves et al. 2014), and phytoplankton diversity (Villac et al. 2008).

In Brazil, the number of studies related to phytoplankton has increased, especially in the new century (Nabout 2015). However, there are no records of reviews based exclusively on dinoflagellates, which encompass key organisms for primary production of aquatic environments (Reynolds 2006), including toxin-producing species and others related to harmful algal blooms (Cardoso 2012; Naves et al. 2006; Mafra 2014). Given the importance of these organisms for the functioning of aquatic ecosystems, and the need to monitor their distribution, it is essential to know the trends and voids of research involving the group. Moreover, management and conservation strategies lack information to support their actions on this subject.

Therefore, the main objectives of this review are to perform a quantitative and qualitative bibliographic survey of studies on dinoflagellates of Brazil, to present their spatiotemporal distribution from a scientometric perspective, and compare any significant trends found with those of other countries.

\section{Materials and methods}

\section{Obtaining data}

The analysis was based on peer-reviewed articles available through the digital platforms Scopus, Scielo and Web of Science from 5 to 8 September 2016 and 10 February 2017. The papers were selected using a combination of the keywords "dinoflagellate" and "Brazil" in the English language, and "dinoflagelados" and "Brasil" in Portuguese. The survey was then performed only with Scopus because the other databases produced the same or fewer papers for the keywords used.

After reading the abstracts, the papers were selected according to the treatment given to the division Dinophyta, and then tabulated according to relevant information from the perspective of a scientometric review (Fig. 1). The interest of this review was in publications that considered dinoflagellates as central or coadjuvant organisms in their general scope and that they occurred in Brazil. For this reason, some of the articles were excluded from the analysis after reading their abstracts because, although the keywords used in the search were included in their titles, abstracts or keywords, dinoflagellates were not necessarily the subject of the study in question.

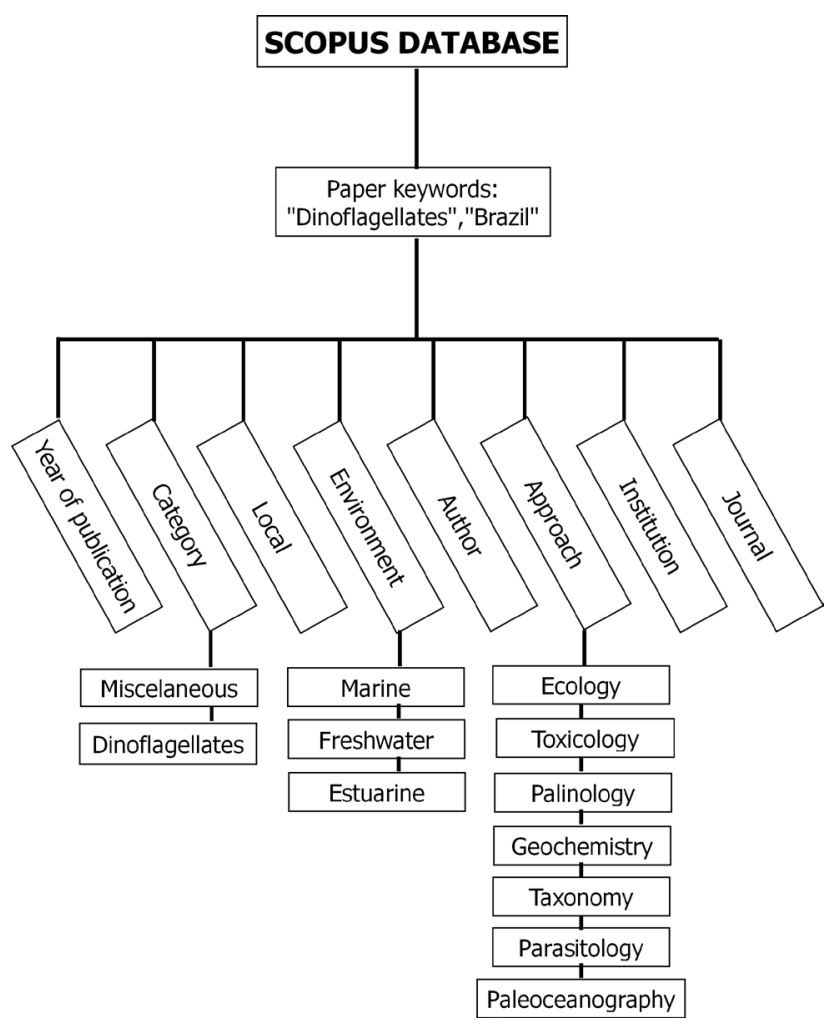

Figure 1. Flowchart indicating the scientometrical information recovered to compose the data matrix after qualifying the papers by reading the abstracts.

\section{Statistical approach}

To determine if there was any temporal trend in the studies with dinoflagellates in Brazil, we performed a simple linear regression of the number of publications over the time-range contemplated. The aim was to test whether there was a significant (alpha of 0.05) increase in the number of publications. A Pearson correlation test $(p<0.05)$ was then performed to determine whether publication frequency was more correlated with the study category "dinoflagellates" or the study category "miscellaneous".

Considering that "study category" is a binary variable in the present study, publications were grouped according to "year category" instead (Tab. S1 in supplementary material). Regarding the qualitative data, information about biological categories was transformed into percentages to assess whether there was bias in: environments studied, institutions and journals that support publication, and the geographical distribution of scientific production.

In order to compare Brazilian productivity to other countries, information data from Scopus were gathered using the country filter for the years of 1990, 2000, 2010 and 2016. Data were then submitted, if not normally distributed, 
to a non-parametric analysis (Kruskal-Wallis test). This method is similar to a classical analysis of variance, but dispenses with the premise of normality. Countries were chosen for comparison based on the number of publications shown by the database.

\section{Results}

A total of 125 peer-reviewed papers were recovered on Scopus for the period of 1990 to 2016. Based on the abstracts, 106 of the papers were selected for this review. Out of this selection, 54 papers dealt exclusively with dinoflagellates, while the other 52 involved other taxonomic groups.

Linear regression significantly explained $\left(R^{2}=0.66 ; p<\right.$ 0.001 ) the variability in the frequency of publications over time (temporal trend), as shown in Figure 2.

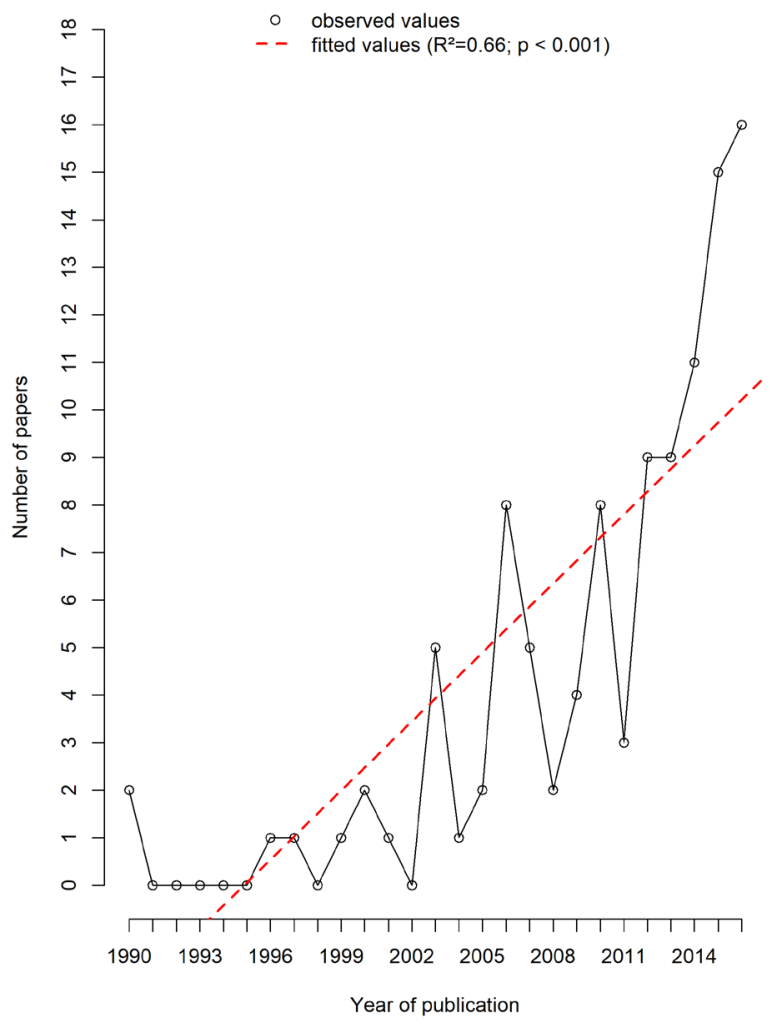

Figure 2. Linear regression between the number of papers selected and the temporal trend of dinoflagellates publications in Brazil.

Three distinct periods in the history of dinoflagellates research can be recognized. From 1990 to 2002 the rate of publication remained low, with a maximum of three publications per year; from 2002 to 2011, the rate of publication fluctuated, yet reaching a maximum of nine per year; and post-2011, the frequency of publications increased continuously. This trend is very similar to other countries (Fig. 3) whose values, in general, were low for the year 1990. For example, The United States only published 34 articles that year, with a 157 produced worldwide. The third period in Brazil is similar to that observed for other countries in terms of increasing, but not with regards to the quantity. While developed countries showed pronounced increases in the number of publications, such as from 34 to 166 in 2016 for the USA, from 13 to 70 for Germany, and from 10 to 85 for France, developing countries constantly increased but at a low rate. Brazilian production, for example, took 26 years to increase the number of publications from one to 34. Likewise, for the same 26-year time interval Argentina went from three to 12, India from one to 24 and Mexico from zero to 16 . Thus, countries can be grouped into two categories regarding their publication trends: i) countries presenting a constant increase, such as Germany, United Kingdom, France, Canada, Australia, China, Deenmark, Netherlands, New Zeland, Norway, Russia, India, Brazil, Belgium, Argentina, Poland and Portugal; and ii) countries increasing until 2010, but then decreasing in 2016, such as the United States, Japan, Spain, Italy, South Korea, Sweden and Mexico. Other small countries were listed in the database, but with less than 10 publications for the period of 1990-2016.

The Kruskal-Wallis test (non-parametric ANOVA) revealed significant differences among the medians of the countries $(\mathrm{p}=0.02)$. It is assumed that values higher than the chi-square model $(\chi 2=34.5)$ are significantly different. Therefore, the United States $(\chi 2=138)$, Japan $(\chi 2=53)$, Germany $(\chi 2=44)$, the United Kingdom $(\chi 2=$ $40)$ and France $(\chi 2=39)$ are statistically dissimilar to the other countries, including Brazil $(\chi 2=8)$. This pattern is illustrated in Figure 3.

Pearson's correlation analysis revealed that both categories (miscellaneous and dinoflagellates) were significant $(\mathrm{p}<0.05)$. However, the correlation parameter $(r)$ was higher for dinoflagellates $(r=0.79)$ than for miscellaneous $(r=0.71)$, indicating that studies specifically on dinoflagellates experienced a more pronounced increase than studies that considered other taxa.

The geographic distribution of the studies in Brazil (Fig. 4 ) is very concentrated in the Southeast and South regions. Rio Grande do Sul (22 publications), Rio de Janeiro (20) and São Paulo (13), were the most productive states. Only three studies were recorded over the entire period in the Amazon region. In the Northeast, the states of Pernambuco (7) and Ceará (5) were the most productive. However, in Ceará, researchers from a foreign university wrote almost half of the papers published there. Federal universities account for the majority of the studies conducted in Brazil (Fig. 4). In the state of Rio Grande do Sul, both federal institutions (FURG and UFRS) represented $20 \%$ of the total studies together.

Most of the papers addressed ecological subjects (47\%), such as the spatial distribution of dinoflagellates and the description of species' ecological functions (Fig. 5). Toxicological aspects were also abundant among the publications (19\%). Most of these were studies regarding 
Pietro Martins Barbosa Noga and Doriedson Ferreira Gomes

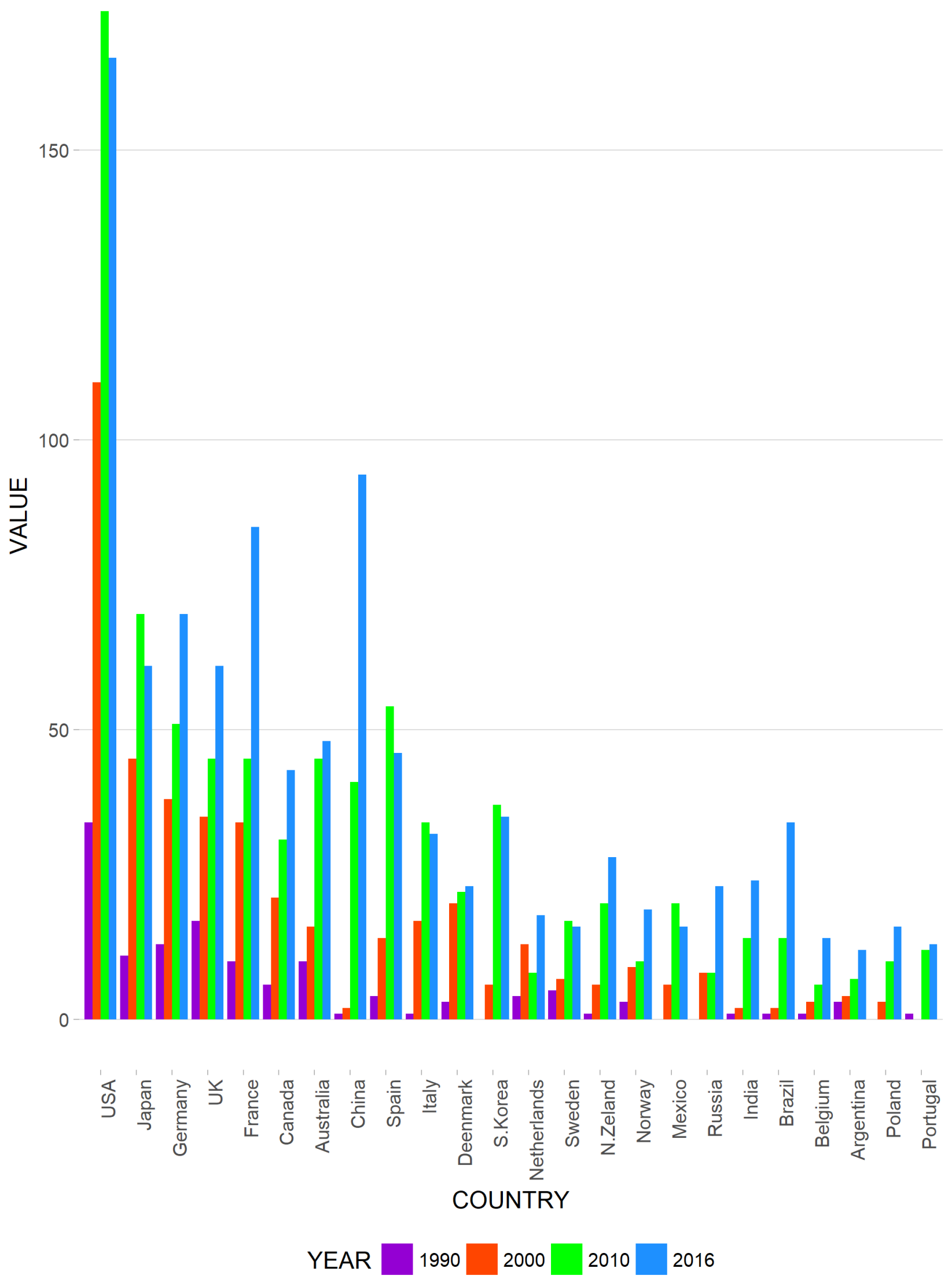

Figure 3. Comparative bar chart indicating the number of papers published per country. Each bar corresponds to a single year, not the sum of the decade. 


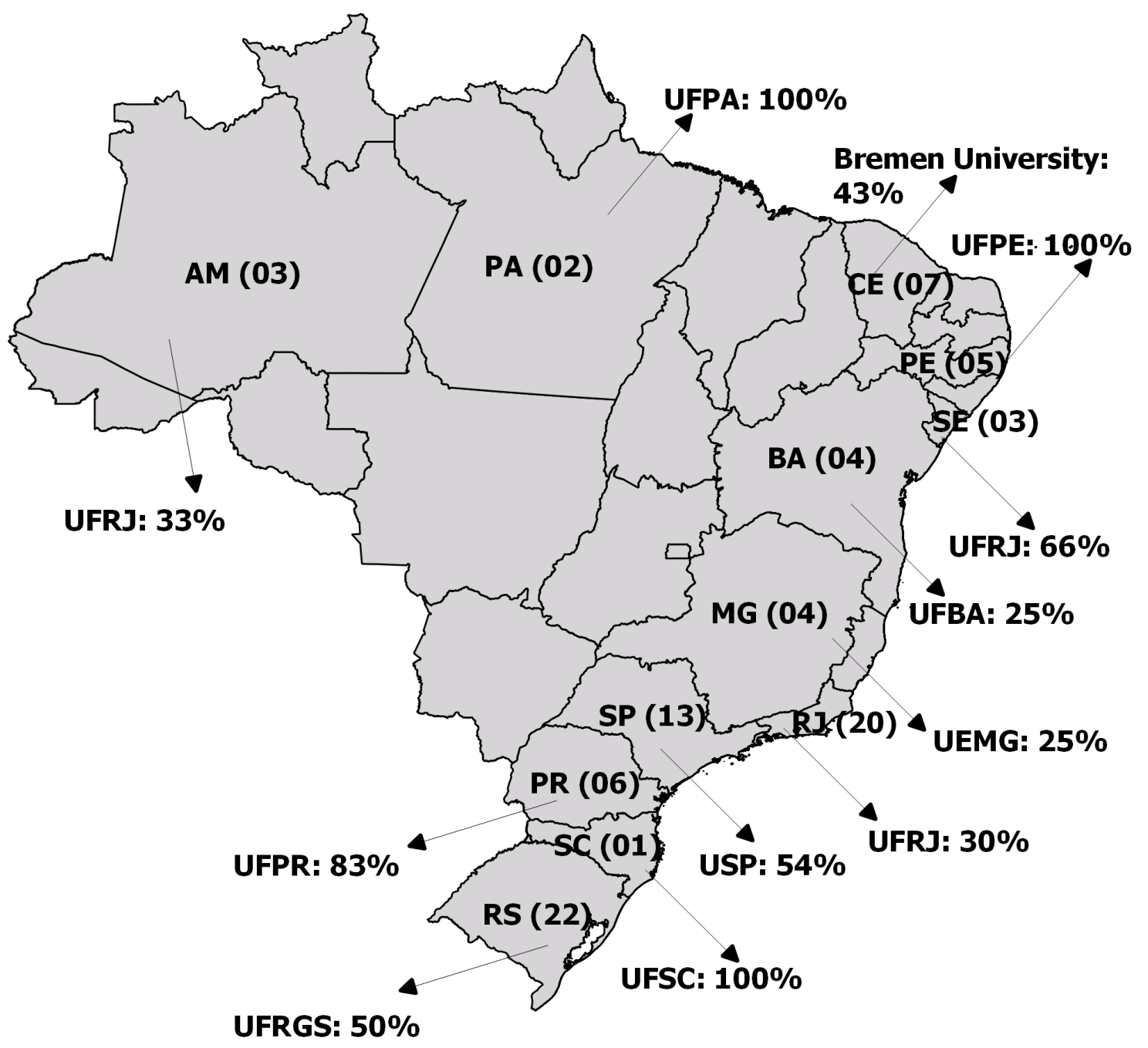

Figure 4. Quantitative characterization regarding the geographic trend in publications about dinoflagellates per Brazilian state between 1990 and 2016. Inside the map: state abbreviation and number of studies conducted there. Outside the map: institutions leading the study and its percent contribution.

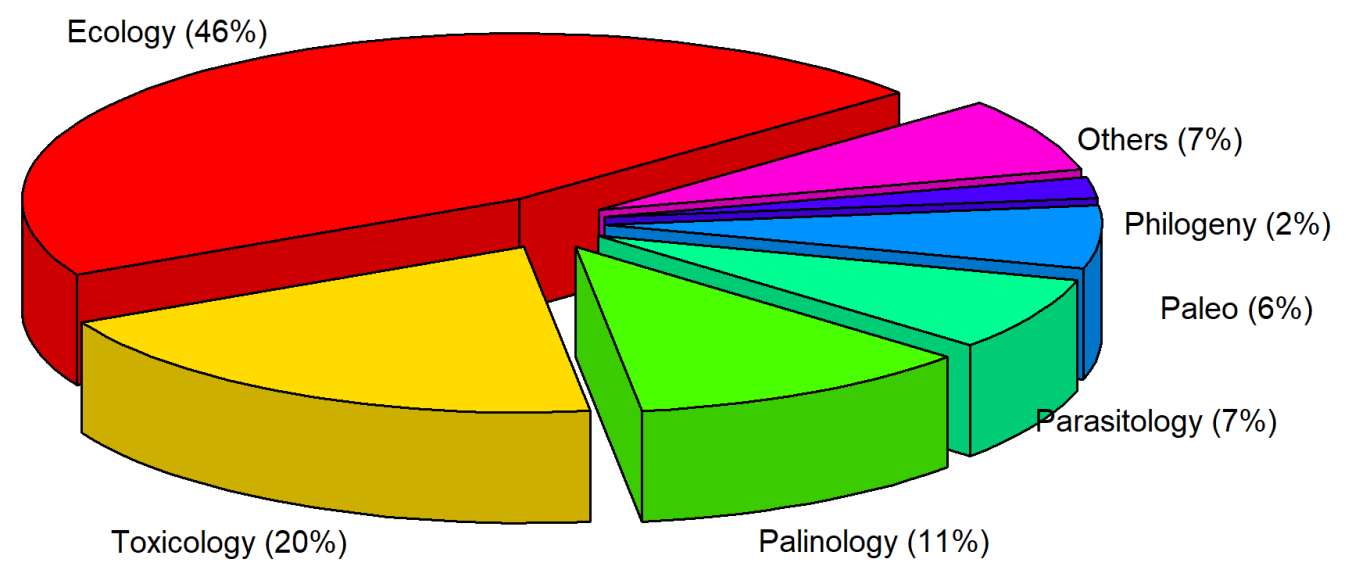

Figure 5. Pie chart displaying the proportion of papers and its scientific approach. 
the toxins inherent to some species of dinoflagellates that are usually associated with algal blooms and pathologies that affect humans and other species. These two categories (ecological and toxicological) accounted for more than $60 \%$ of all publications between 1990 and 2016. Other subjects were also explored, but less frequently: palynology (11\%), parasitology (7\%) and paleoceanography (6\%).

Considering the category "dinoflagellates", most of the papers took place in marine ecosystems. On the other hand, for the category "miscellaneous", the most studied ecosystem was "freshwater". The number of studies performed in estuarine ecosystems was low for both categories (Fig. 6).

\section{Discussion}

The number of studies on dinoflagellates in Brazil increased from 2002 to 2016, as shown in Figure 1. This temporal trend is certainly related to the recent increase in investment in science, which is also reflected in an

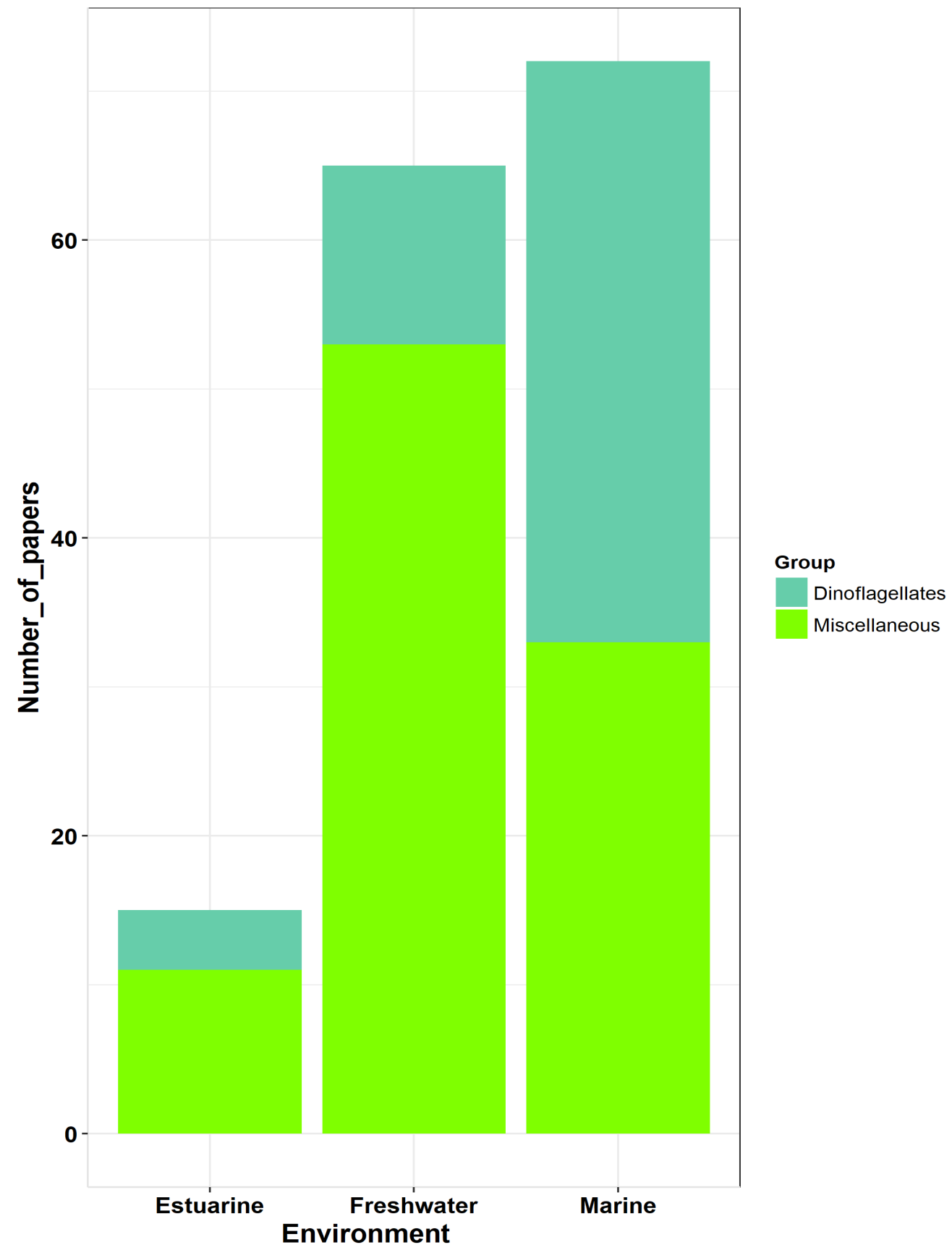

Figure 6. Bar chart between the number of publications regarding the biological category and the ecosystem where the study was conducted. The light green bars represent studies contemplating various taxonomic groups and the dark green bars represent studies exclusively on dinoflagellates. 
increasing number of public universities responsible for approximately $95 \%$ of Brazilian papers (INEP 2015), as well as an increase in the number of research groups involved (Glanzel et al. 2006, Leta 2012, Sidone et al. 2016). This trend has certainly resulted in greater representation of Brazil in South America, and an increasing, yet minor, representation worldwide. Although there has been an increase in indexed publications, Brazilian science is still far from the production of most developed countries, such as the United States, Japan and European countries. This tendency was also verified by another database (Science Criterion Index) in which all of Latin America contributed only $5 \%$ to the total number of publications produced between 1990 and 2000 (Holmgren \& Schnitzer 2004). It is true that the number of publications is not necessarily the best parameter for discussing scientific productivity, but it is a good initial index of research status.

The results of the Kruskal-Wallis test revealed that there are significant differences in productivity among countries. The United States, Japan, Germany, the United Kingdom and France are statistically different from other countries in research involving dinoflagellates (Fig. 3). These countries invest a much greater portion of their gross domestic product (GDP) in R\&D compared to Brazil. For example, Japan invests $3.4 \%$ while Brazil invests only $1.3 \%$. Albornoz (2001) suggests that, as a group, Latin America could invest much more of its resources in $R \& D$.

The increase in the number of studies with dinoflagellates observed herein can be related to an increasing trend in the number of publications about phytoplankton communities, which, although rising, still indicate the late stage of Brazilian science, compared to the most productive countries in this field. The national range for phytoplankton research production was 0-14 publications per year, while for the same period the global range was 3-71 (Nabout 2015). Another explanation for the increase in the number of papers on dinoflagellates could be the fact that harmful dinoflagellate blooms are mainly responsible for human intoxication on coastal areas (Fleming et al. 2006). Therefore, environmental conservation studies due to these bloom events are expected to receive more investment, and thus continue to increase in publication production.

The number of studies on dinoflagellate species increases in a more pronounced and constant way over time than does the number of studies of phytoplankton as a whole, as demonstrated by the Pearson correlation analysis. This result may be underpinned by the fact that interest in these organism increases as interest in their toxic potential increases. That is, the number of publications interested in functional ecology has been increasing, and many publications have focused on toxin-producing species related to harmful algae blooms. Searching for the keywords "dinoflagellate" and "toxic", the number of studies went from zero in 1990 to 12 in 2017. This is a low increase, and number, compared to the United States (from 13 to 229 in the same period), but relatively high compared to the number of publications retrieved with only the keyword "dinoflagellate".

The spatial analysis revealed that publications involving dinoflagellates are mostly concentrated in the South and Southeast regions of Brazil. This is mainly due to the large representation in these regions of institutions that hold the largest research centers, with the greatest number of graduate programs, which are responsible for the scientific production in these regions. According to Leta (2012), universities hold $90 \%$ of researchers with a master's degree and among the ten most productive institutions in the country nine to ten of them are universities. According to the CAPES georeferenced information system (https:// geocapes.capes.gov.br/geocapes/), in 2000 the states of Rio de Janeiro and São Paulo possessed 726 postgraduate programs, corresponding to $50 \%$ of the total for the country. In 2016 this value went to 1,801, while states in the North region, like Amazonas and Pará, went from only 10 and 21 to 58 and 107, respectively, in spite of the Amazon region being a conservation hotpost. This biased distribution of resources corroborates the low results for Brazilian science, and indicates a need to stimulate scientific development in a more egalitarian way.

The results concerning environments indicated the dominance of phytoplankton studies in Brazilian continental freshwater ecosystems. This result is likely related to the fact that, in Brazil, the human water supply comes from rivers or reservoirs, the latter of which is often faced with phytoplankton blooms resulting from the poor management of the body of water (Azevedo et al. 2002). There have been two nationally known cases of human death due to contamination of water from toxic blooms (Azevedo et al. 2002). On the other hand, the global trend reflects a predominance of phytoplankton studies in marine environments (Nabout 2015). In this survey, studies regarding dinoflagellates were more abundant in marine systems. This can be explained by the predominance of dinoflagellate species (about $90 \%$ ) in this environment (Falkowski 2004; Taylor et al. 2008).

Nevertheless, Brazil has an increasing trend in studies of dinoflagellates as a consequence of the greater availability of federal and state funding for research in recent years, in addition to the growth of graduate programs. However, it is necessary to distribute sampling efforts more evenly throughout the country. Another aspect that needs to be considered is investment in biodiversity and ecology research, since the study of cryptic species has emerged as a constant issue. It should also be pointed out that tropical systems are, as a rule, less studied, yet they have greater species richness (Mora et al. 2003; Tittensor et al. 2010; Yasuhara et al. 2012). There remains a vast field for discovering new species and addressing relevant questions for the development of science. 


\section{Acknowledgements}

We thank the Foundation for Research Support of the State of Bahia - FAPESB (Call Notice No 09/2012, Application $N^{\circ} 1356 / 2012$ ) for granting a master's degree scholarship to P.M.B.N. We also are grateful for the collections under projects PET 0030/2012 and 0039/2012, and RED0026/2014, and the anonymous reviewers who contributed to improving the manuscript.

\section{References}

Albornoz M. 2001. Science and technology in Latin America: An overview. San Francisco,Annual Meeting of the American Association for the Advancement of Science.

Alves MTR, Teresa FB, Nabout JC. 2014. A global scientific literature of research on water quality indices: trends, biases and future directions. Acta Limnologica Brasiliensia 26: 245-253.

Annan K. 2003. A challenge to the world's scientists. Science 299: 14851485.

Azevedo SM, Carmichael WW, Jochimsen EM, et al. 2002. Human intoxication by microcystins during renal dialysis treatment in Caruaru-Brazil. Toxicology 181: 441-446.

Cardoso LS. 2012. Bloom of Noctiluca scintillans (Macartney) Kofoid \& Swezy (Dinophyceae) in southern Brazil. Brazilian Journal of Oceanography 60: 265-268.

Falkowski PG, Katz ME, Knoll AH, et al. 2004. The evolution of modern eukaryotic phytoplankton. Science 305: 354-360.

Fleming LE, Broad K, Clement A, et al. 2006. Oceans and human health: Emerging public health risks in the marine environment. Marine Pollution Bulletin 53: 545-560.

Glänzel W, Leta J, Thijs B. 2006. Science in Brazil. Part 1: A macro-level comparative study. Scientometrics 67: 67-86.

Holmgren M, Schnitzer SA. 2004. Science on the rise in developing countries. PLoS Biology 2(1): e1. doi: 10.1371/journal.pbio.0020001

INEP - Instituto Nacional de Estudos e Pesquisas Educacionais Anísio
Teixeira. 2015. Sistema Nacional de Avaliação da Educação Superior (Sinaes). v 5. Brasília, INEP. http://www.publicacoes.inep.gov.br

Leta J. 2012. Brazilian growth in the mainstream science: The role of human resources and national journals. Journal of Scientometric Research 1: 44-52.

Mafra LL, Tavares CPS, Scharam MA. 2014. Diarrheic toxins in fieldsampled and cultivated Dinophysis spp. cells from southern Brazil. Journal of Applied Phycology 26: 1727-1739.

Melo AS, Bini LM, Carvalho P. 2006. Brazilian articles in international journals on limnology. Scientometrics 67: 187-199.

Mora C, Chittaro PM, Sale PF, et al. 2003. Patterns and processes in reef fish diversity. Nature 421: 933.

Nabout JC, Carneiro FM, Borges PP, Machado KB, Huszar VLM. 2015. Brazilian scientific production on phytoplankton studies: national determinants and international comparisons. Brazilian Journal of Biology 75: 216-223.

Naves JL, Prado MP, Rangel M, Sanctis B, Machado-Santelli G, Freitas JC. 2006 Cytotoxicity in the marine dinoflagellate Prorocentrum mexicanum from Brazil. Comparative Biochemistry and Physiology Part C: Toxicology \& Pharmacology 143: 73-77.

Padial AA, Bini M, Thomaz SM. 2008. The study of aquatic macrophytes in Neotropics: a scientometrical view of the main trends and gaps. Brazilian Journal of Biology 68: 1051-1059.

Reynolds CS. 2006. The ecology of phytoplankton. Cambridge, Cambridge University Press.

Sidone OJG, Haddad EA, Mena-Chalco JP. 2016. A ciência nas regiões brasileiras: evolução da produção e das redes de colaboração científica. Transinformação 28:1-19

Taylor FJR, Hoppenrath M, Saldarriaga JF. 2008. Dinoflagellate diversity and distribution. Biodiversity and Conservation 17: 407-418.

Tittensor DP, Mora C, Jetz W, et al. 2010. Global patterns and predictors of marine biodiversity across taxa. Nature 466: 1098.

UNESCO. 2001. The state of science and technology in the world, 19961997. Montreal, UNESCO Institute for statistics.

Villac MC, Cabral-Noronha VAP, Pinto TO. 2008. The phytoplankton biodiversity of the coast of the state of São Paulo, Brazil. Biota Neotropica 8: 1-3.

Yasuhara M, Hunt G, Dowsett HJ, Robinson MM, Stoll DK. 2012. Latitudinal species diversity gradient of marine zooplankton for the last three million years. Ecology Letters 15: 1174-1179. 